Dioxin exposure

\section{CDC study still at square one}

Washington

A $\$ 60$ million epidemiological study of the health consequences of exposure to contaminated defoliants by dioxin used during the Vietnam war has been suspended, and may be cancelled before it can ever get under way. Who will make the final decision to proceed, and even when the decision will be made, is still unclear.

Agent Orange was the code name for a defoliant agent used by US forces during the Vietnam war. One contaminant of Agent Orange is known to have been the dioxin isomer 2,3,7,8-TCDD, a known carcinogen in animals. But the health effects of dioxins in humans have been the subject of long and heated debates. Even studies of acute high-level exposures have given equivocal results, confirming that the possible health effects of long-term low-level exposure to toxic agents cannot easily be answered.

Although the skin disease chloracne is the only clear-cut health problem in humans, studies have implicated liver disease, soft-tissue sarcomas and birth defects in children of exposed adults. But an Air Force study of soldiers actually involved with Agent Orange spraying, termed the Ranch Hand study, failed to uncover health problems unequivocally associated with the defoliant.

Still, anecdotal evidence for the effects of Agent Orange from Vietnam was strong. Under pressure from veterans' groups, Congress in 1979 declared that a study should be done to provide definitive answers. The Veterans Administration was the natural first choice for the agency

\section{Hewlett thanks Stanford University}

\section{Washington}

IN one of the more generous gestures of alumni appreciation, William Hewlett last week gave Stanford University \$50 million, the largest individual commitment the California institution has received in its 100-year history. The gift from the co-founder of the HewlettPackard company will help to revive Stanford's sagging research facilities and increase financial awards for the university's 12,000 students.

Hewlett's pledge will also be used to mark the inauguration of his university's centennial campaign, which formally begins in 1987. Hewlett and Stanford's president, Donald Kennedy, have been discussing its dispensation for at least two years, with some clearly defined results. All but $\$ 10$ million of Hewlett's gift will be ploughed into the 41 -acre Near West campus, between the main campus and Stanford's medical research facilities. to carry out the study. But those concerned about conflicts of interest argued that the study should be moved to the control of the Centers for Disease Control (CDC) at Atlanta, Georgia.

Initially, CDC were alarmed that it might be impossible to find a large enough cohort of soldiers who had not been exposed to Agent Orange. As things worked out, just the opposite was the case. Records of troop movements failed to yield easily interpretable data for assessing the exposure of individual soldiers.

Carl Keller, chairman of the science panel of the Agent Orange Working Group (AOWG), says the difficulties are "horrendous". AOWG is the executive branch group charged with looking into the long-term health effects of herbicides. The Under Secretary of the Department of Health and Human Services (HHS) chairs AOWG, and ultimate responsibility for seeing that the Agent Orange study is "scientifically valid" falls to him. Donald Newman, who joined HHS last year is still awaiting Senate confirmation as under secretary.

Meanwhile, Congress charged the Office of Technology Assessment (OTA) with the assessment of CDC's protocols. By law, no study can proceed without OTA's blessing. CDC's proposed study had originally consisted of three groups of 6,000 subjects each; a high-exposure group, an unexposed combat control group and a non-combat unexposed group. But finding combat controls proved easier than expected, so last November, CDC presented OTA with a new

Although space attractions have yet to be worked out, university planners expect to tear out 300,000 square feet of the campus's 725,000 total building area, and to add $\mathbf{8 0 0 , 0 0 0}$ square feet of floor space specifically designed for the new equipment included in renovation blueprints.

Stanford's research rejuvenation will cost $\$ 250$ million in total, and will be completed within a decade. The university will use the remaining $\$ 10$ million of Hewlett's pledge to establish endowed undergraduate scholarships and graduate fellowships.

William Hewlett has a history of beneficence to Stanford, whose endowment already nears $\$ 2,000$ million. But the 1934 graduate may have good reasons for his gratitude: it was at Stanford that Hewlett first met David Packard and forged the friendship that has grown into a billiondollar business whose headquarters remains a few miles away. Karen Wright protocol, calling for only two cohorts of 6,000 subjects each. CDC planned to start interviewing prospective study participants in January this year, with extensive physical examinations to follow. But OTA balked, saying that CDC had failed to establish adequate exposure criteria and did not address problems associated with mis-classification of an individual's exposure history. At OTA's suggestion $\mathrm{CDC}$ agreed to postpone further activity until these issues could be resolved.

AOWG's efforts to help CDC settle the exposure issues seems to have backfired. AOWG formed a subpanel, chaired by Alvin Young of the White House Office of Science and Technology Policy, to review possible solutions, but the selection of Young raised concern that the momentum of the Agent Orange study might be waning. Young, who is described as having grave doubts that any workable exposure measurements can be found, declines to comment on the deliberations of his panel.

Finding an acceptable exposure measure is crucial to the CDC study, but nobody thinks that will be easy. Peter Layde, acting director of the Agent Orange programme at CDC, says that there is no obvious reason why one measure should be more meaningful than another, and that the many exposure estimates used so far have so much variability that they are meaningless.

For veterans' groups, the delay has been frustrating. "Confusion over data on exposure should have been resolved a long time ago", says John Terzano of the Vietnam Veterans of America, who is anxious to have a study that people will listen to even if they do not agree with it.

Some new information on the health effects of Agent Orange exposure will come from other studies under way at CDC. The Vietnam Experience study compares 2,000 in one group of people who served in Vietnam with another 2,000 whose military service was elsewhere. A case control study of soft-tissue sarcomas will shed some light on possible links between Agent Orange exposure and cancer.

$\mathrm{CDC}$ would like to begin physical examinations of participants in the Agent Orange study in June, when the Lovelace Clinic in New Mexico will be finished with the Vietnam Experience Study examinations. But after Young's group makes its recommendations, $\mathrm{AOWG}$ must approve them and transmit them to CDC. CDC must then change to a new protocol, and OTA must then evaluate it. For all that to happen by June needs unusually quick action.

Keller concedes that $\mathrm{AOWG}$ or $\mathrm{CDC}$ may decide it is not possible to quantify indirect exposures, so no meaningful study can be undertaken. But if that is the decision, warns Terzano, "a very, very serious problem is brewing". Joseph Palca 